\title{
Understanding the Mental and Physical Health Needs and Acculturation Processes of International Graduate Students in the United States
}

\author{
Mehrete Girmay $^{\mathrm{a},{ }^{*}, \text { Gopal K. Singh }}{ }^{\mathrm{a}}$, Sosanya Jones ${ }^{\mathrm{b}}$, and Juliane Wallace ${ }^{\mathrm{c}}$ \\ ${ }^{a}$ Department of Health and Human Services, United States; ${ }^{b}$ Howard University, United States; ${ }^{c}$ Southern Illinois \\ University Carbondale, United States; \\ *Corresponding author: Email: mgirmay@hrsa.gov \\ Address: Health Resources and Services Administration, Office of Health Equity, US Department of Health and Human Services, \\ 5600 Fishers Lane Rockville, MD 20857, United States
}

Received 4/10/19; revised 5/18/19; revised 5/19/19; accepted 9/4/19

\section{Introduction}

In 1950, the number of international students receiving their graduate education in the United States was $1.1 \%$. Forty years later, that number grew to $2.9 \%$. According to a report published in 2015 through the Institute of International Education, the number of international graduate students in the U.S. was $37.2 \%$ during the 2014/2015 academic year (Institute of International Education 2015). This number is indicative of what the future looks like in terms of international graduate students opting to attend U.S. universities for their graduate education. For the purposes of understanding the challenges that international graduate students face, the umbrella term of Acculturation served as a guiding construct during this study. Broadly, acculturation can be understood as the cultural socialization process that an individual undergoes as they navigate their way through a new environment and society (Kim and Omizo 2006).

Another construct that helped in guiding this research was Cultural Competence in regard to the ways in which the host university staff seek to meet the emotional and physical needs of their visiting students. Cultural Competence is an ongoing process and is essentially, a set of congruent behaviors, attitudes, and policies that align in a system, agency, or professions to work effectively in cross-cultural situations (Cross 1989). For international graduate students, it is especially challenging to acculturate as their academic requirements and demands differ from that of a domestic or undergraduate student (Sullivan and Kashubeck-West
2015). In order to gain insight as to what is needed to provide the international graduate student with opportunities to successfully adjust to their host university's culture, several key factors should be explored: stress and its management techniques/strategies, lack of social connectedness, financial stressors, language fluency/barriers, and academic challenges/difficulties. The heightened distress that international graduate students experience during their time abroad is affected by multiple and confounding factors (Chen, Liu, Zhao, and Yeung 2015; Erichsen and Bolinger 2010). Cultural dissonance coupled with an inability to communicate with other students and staff at the host university plays a role in the international student's adjustment experience (Erichsen and Bollinger 2010).These obstacles in adjusting to a new culture, language, and academic environment, which stem from emotions of social isolation, being homesick, and culture shock, to name a few, all have the ability to affect how well the student adjusts (Baba and Hosada 2014).

As international graduate students sojourn from their home country to the U.S. to embark on their graduate career, there are many adjustment challenges that they encounter. As researchers Sullivan and Kashubeck-West (2015) explain, the difficulties that international students experience is more extensive in nature as they face pressures in their adjustment process that deal with cultural differences in the academic learning environment and style in addition to language barriers (Baba and Hosoda 2014). As an increase in mobility continues, there has also been an increase in international students attending universities in the United States. 
Furthermore, as the trend in institutions of higher education promoting internationalization increases, the importance of understanding this population's needs subsequently gains importance. Thus, it was critical that the data gathered from the study would be able to answer these four research questions: 1) What are the academic and social adjustment needs of first time U.S. entering international graduate students at the host university?; 2) In what ways do these needs affect the mental and physical health of international graduate students as they acculturate?; 3)What services does the host university offer and/or need to expand upon in order to ensure that the needs of international graduate students are being met, primarily in regards to their mental health?; 4) What are the gaps in services to address the needs of international graduate students at the host university?

It is important to note that there are several ways in which the international graduate student provide benefits to the host university. International students offer opportunities for diversity on university campuses, which in turn affords domestic students' exposure to other cultures (Billings and Terkla 2014). Institutions of higher education are increasingly valuing diversity on their campus and are understanding that global outreach will also serve their academic reputation well (Chen et al. 2015). In addition to academic related benefits are financial ones. Unless international students have a graduate assistantship, they typically pay the full tuition amount of the host university, which helps to subsidize fees of their domestic student colleagues (Chen et al. 2015).

The main purpose of this study was to gain an indepth understanding of the adjustment needs of international graduate students at the host university. Additionally, the goals of this qualitative, narrative case study were to first explore the needs of international graduate students in regard to their adjustment in obtaining their graduate degree at a public university located in Illinois and how both their mental and physical health were affected. Currently, at the case-study university, there are over 98 countries represented by both undergraduate and graduate students. During the 2015/2016 academic year, there were 1400 international students enrolled during, with $2 / 3$ being graduate students. As this number continues to rise in conjunction with shifting societal factors that have the potential to affect the international graduate students experience while at the university, it is important that University staff, which include but are not limited to full and parttime employees who work in (on and off) campus housing, student affairs, security, student rights and responsibilities, as well as community members, are aware of the particular needs attached to this population and the ways in which they can play a role in fostering a welcoming environment.

\section{Objective}

The main purpose of this study was to gain an indepth understanding of the adjustment needs of international graduate students at the host university. There are, of course, a variety of factors that play a part in the adjustment needs that plague international graduate students and their adjustment to the host university. Consequently, in order to adequately meet the needs of this population, these factors should be understood both independently and collectively. As the number of international graduate students migrating to the U.S. continues to increase, it is critical that host university staff and domestic students work toward creating sustainable efforts that will adequately meet both the emotional and physical needs of this population. Moreover, this is both a timely and timeless topic that allows for personal introspection in eliminating any underlying bias, stereotypes, discriminatory beliefs and practices.

\section{Literature Review}

The behavioral dimension of acculturation involves the international graduate student becoming increasingly knowledgeable of the values, practices, and customs of the host university. The cognitive or psychological dimension allows for the emotional attachment that the individual experiences within the host culture to be 
strengthened through these new cultural changes (Capielo, Delgado-Romero, and Stewart 2015). Many of the acculturating factors have the ability to be confounding in nature. For example, language barriers may lead to confusion and anxiety for the international graduate student due to difficulty with course material and assignments (Bai 2016). This, in turn, typically conjures up feelings of isolation and alienation (Erichsen and Bollinger 2010).

Acculturation should be understood as a process, while not attaching a positive or negative connotation to it. Principally, acculturation can be conceptualized through both unidimensional and bidimensional approaches. The unidimensional approach proposes that an inverse relationship is present between the individual and culture, while the bi-dimensional approach takes into account the identification that the individual attaches to their new environment (Shim, Freund, Stopsack, Kämmerer, and Barnow 2014). Additionally, in using Berry's conceptualization of acculturation, which assumes that acculturating individuals are all confronted with the same two dilemmas, a clearer portrayal of the needs of international graduate students was garnered. (Shim et al. 2014; Berry 2009).

The first dilemma involves the willingness of the individual to maintain bonds with their home culture. The second dilemma focuses on whether or not the individual deems it valuable to maintain relationships with those of other cultural groups (Shim et al. 2014). Acculturative stress is the characteristically negative reaction that international graduate students experience in response to their new identity and as their behaviors and values change. The relationship between acculturative stress and mental health is an important area to explore as the international graduate student's psychological maladjustment can affect their overall acculturation experience at the host university (Berry 2009). The effects of acculturative stress are not only long lasting but also typically get to crisis level within the first six months of the student arriving at the host university (Chalungsooth and Schneller 2011).

A primary hardship and challenge encountered by international graduate students while studying in the U.S. is the culture shock that they experience (Chapdelaine and Alexitch 2004). Culture shock involves both the adjustment and adaptation processes that the international student experiences as they deal with behavioral, cognitive, and demographic factors (Erickson and Bollinger 2011). It has been suggested by researchers that the length of stay at the host institution has an effect on the student's acculturation as they have more opportunities to assimilate into the host culture; the longer the international student stays in the host country, the more acculturated they will be. This is an issue for graduate students in particular, as their academic programs typically last for a duration of two to five years.

Social support also helps in the alleviation of feelings of homesickness, which is a result of culture shock (Hirai, Frazier, and Syed 2015). Furthermore, homesickness is an inevitable part of the acculturation process and, therefore, experienced by the international student regardless of their prior knowledge and exposure to U.S. culture. Cross-cultural adjustment is essentially the response that the international graduate student has to their new environment as they attempt to adapt and function within it (Hendrickson, Rosen, and Aune 2011). As we relate this process to acculturation, we can understand that an intercultural adaptation occurs for the international student upon their arrival to the new environment.

There are several personal and institutional barriers to the international graduate student seeking professional help, primarily for emotional stressors (Blignault, Ponzio, Rong, and Eisenbruch 2008). These barriers involve the international student experiencing feelings of shame, fear of stigma, lack of awareness of what services the host institution offers, and cost of services. The institutional barriers, simply put, have to do with the availability of mental health services for ethnic minorities (Blignault et al. 2008). Many international students are mistrustful of the mental health professionals on their campus as they expect cultural differences to play a significant role in the services that they receive (Mori 2000). Furthermore, the fear that the international graduate student might have regarding seeking professional help for mental health issues has 
much to do with their home countries view on mental health and counseling (Blignault et al. 2008). Therefore, it is critical that the host university seeks out their visiting students and educates them on their health care options. In addressing these gaps in services, the host university will be better able to meet the overall needs of international graduate students.

\section{Methods}

After recruiting 15 international graduate students from the student body and narrowing down to 10 , we held two focus group sessions followed by individual interviews with each participant. In order to get the richest data, we asked participants to share their experiences since arriving at the host university. The primary factors that we focused on in my questioning process were centered on the student's health and included: 1) academic, social, and financial stressors; 2) social connectedness and support; 3) language proficiency; and 4) culture shock. All ten participants were English speakers, thus not requiring a translator and were made aware that their participation was voluntary. In order to protect the identities of each participant and promote confidentiality, pseudonyms were ascribed to each participant. The data collection and subsequent analyses procedurally consisted of two stages. We began by holding two focus group sessions, the first with the five female participants and the second with the five male participants (Table 1). During both focus group sessions, which lasted an hour and a half, participants were prompted with questions designed to elicit dialogue regarding their experiences while at the host university. As the focus group sessions were performed online,weI were able to use, in sequential order, Open, Pattern, Values-based, and Emotional coding during the data collection process. All four coding methods served as tools to gain a deeper understanding of not only what the participants were saying but also the way in which the words were said, essentially observing their mannerisms while cautious to not attach meaning to them.
Following both focus group sessions, hour long oneon-one semi-structured interviews were held with each of the participants in order to delve deeper into thoughts previously shared with the larger group. Since narrations refer to personal experience, the individual interviews provided an opportunity for me to hear the participant's stories regarding experiences that have taken place during their acculturation to the host university. This technique allowed for an understanding of participant experiences and, furthermore, a reconstruction of events that have taken place from the perspective of the participants. This research project was reviewed and approved by the host university's Human Subjects Committee.

\section{Background of Participants}

There were ten (five female and five male) international graduate students that participated in this study, seven of which were doctoral students and three master's level students (Table 1). In garnering participation from participants from varying backgrounds and majors, differing perspectives were shared regarding adjustment experiences as it related to their upbringing, cultures, and their respective departmental academic demands.

Table 1: Participant Information

\begin{tabular}{|c|c|c|}
\hline Name & Country of Origin & Degree to be Awarded \\
\hline Liana & Bangladesh & Masters \\
\hline Jill & Nigeria & Ph.D. \\
\hline Patricia & Mongolia & Masters \\
\hline Myra & India & Ph.D. \\
\hline Jenn & Zambia & Ph.D. \\
\hline Michael & Nigeria & Ph.D. \\
\hline Ryan & India & Ph.D. \\
\hline John & Japan & Masters/Ph.D. \\
\hline Stephen & Colombia & Ph.D. \\
\hline
\end{tabular}




\begin{tabular}{l|l|l} 
Kyle & Nepal & Masters
\end{tabular}

\section{Results}

The six themes that emerged during both focus group sessions and the individual interviews involved five rounds of coding. The themes (Loneliness and Isolation, Social Media, Mental Health Support, Professor and Student Dynamic, Financial Stability, Overall University Support) that emerged from the participant's stories are a direct reflection of what these international graduate students experienced as they adjusted to the university as well as the surrounding community. These themes also include the emotions that are attached to participant experiences, which incorporate their upbringing, morals, and beliefs. Critical Social Theory was used to understand how social issues affected feelings of inequity on behalf of the participants. I also used Critical Race Theory in Education to both explore and address how the ethnicity of the participants related to their academic experiences and, furthermore, how institutional inequities contributed to their acculturation experiences.

The most poignant emotions that were expressed by participants were centered on loneliness and isolation. All ten of the participants shared that they had experienced some form of social isolation since entering graduate school, especially during the period of their initial arrival. The social isolation that they experienced was multifactorial and confounded, at times, by other adjustment stressors. In order to understand the first theme, Loneliness and Isolation, we explored the multiple layers involved. There were three sub-themes that emerged, which were: 1) Social Isolation 2) Interpersonal Isolation 3) Academic Isolation 4) New Environment Loneliness 5) Cultural Loneliness. Each sub-theme provided a more in depth look into the differing ways in which loneliness and isolation affected the participants. An example can be found in that many of the participants explained that they migrated from societies that were more collectivist in nature and were forced to quickly adjust to American societal practices. As one of the participants Jill (Nigeria, Ph.D.) explained,
"African people are social and everyone wants to be family." She shared that in Nigeria, people are more communal while American culture promotes independence. She further shared that adjusting to the difference in culture had been so overwhelming that she decided very early on in her arrival at the host university, that while she would remain open to building connections with domestic students, she would mostly invest in forging friendships with other international students. This decision served her well as she explained that the connections she created with other African international graduate students, specifically, helped remedy some of her adjustment challenges to the university and surrounding community.

Another female participant, Liana (Bangladesh, Master's) shared that she too had experienced social isolation that stemmed from loneliness. Coming from a tightknit family base in Bangladesh, she found it quite difficult to navigate her way in a culture that was so different from what she was used to. She shared that due to her not having any family or many friends to enjoy outings with, her routine had become repetitive in that her daily schedule typically consisted of going to class and back home to study. During the focus group, she shared "There has been no formal conversations with classmates, so I began to concentrate on my studies and research." The lack of social interaction was a very challenging adjustment for Liana to make. She said, "We are all social beings that need to be around others in order to survive." Similar to both Jill and Liana, Myra (India, $\mathrm{Ph} . \mathrm{D}$.) also shared her experiences of loneliness and social isolation while at the host university. Myra attributed her feelings of isolation from non-international students to differing cultural practices. According to her, in Indian culture, people desire to help one another, even strangers. She explained, "Everyone has their own life in America and if you need help, you have to ask for it." She also shared that in coming from a culture "Where people help their neighbors if they are struggling to now living in America, where people don't necessarily go out of their way to help someone" was a culture shock. During the focus group, Myra expressed that the independent nature that she believes Americans ascribe to, has served as a barrier in allowing relationships to be 
formed with international students and, furthermore, the ability to learn about other cultures. For Myra, the mealtime custom differences were particularly difficult to adjust to. She explained that in India, meal-times are considered opportunities for laughter and sharing updates with one another. She was surprised to witness American students eat their lunch separately. She said, "I have learned that food is such an important part of our society. Eating food without socializing, is new for me. It was very disconcerting to come here and notice that people don't share foods or lunches, like a peace offering." She went on to share how culturally beneficial it would be for domestic and international graduate students, alike, to share their meals with one another and that the educational exposure would be mutually beneficial.

Male participant, Michael (Nigeria, Ph.D.) explained that he had several experiences where American students were hesitant to respond to his initiation of conversation and when they did it was only to "appear friendly," but not necessarily interested. During his one-one-one interview, Michael elaborated on his experience with social isolation. He shared an example of a time when he ran into a classmate outside of the academic setting and when Michael greeted him, the person responded with a cold-natured "hello." This experience shaped Michael's view on domestic students and American culture. $\mathrm{He}$ explained that this single encounter deterred him from ever initiating conversation with domestic students again. He shared, "I am very picky with whom I call my friends" and ultimately was not eager to seek out what he deemed were "forced friendships" with American students.

The stress related to academic achievement also played a role in perpetuating another type of loneliness, Academic loneliness. During the focus group, Myra explained that the most challenging aspect of her adjustment was getting used to the difference in academic structure and overall academic environment at the host university. Though she grew to appreciate the American educational system, she explained that her first few months at the university were intimidating. She said, "I called my mom every day saying, 'I'm so dumb because all of the American kids would talk so smart and intelligent in class." This intimidation, she explained, forced her to experience levels of isolation as she dedicated more time to her studies. Similar to Myra, Michael shared that the differences in the academic structures between Nigeria and the U.S. was a challenge that he struggled to overcome. He said, "The work here is much harder," which forced him to dedicate more hours to his studies and consequently attend fewer social events. He said, "In America, the students are being prepared for graduate school and to do well," which he explained is not the case with early education in Nigeria. He said that upon noticing this educational difference, he began to push himself to "work harder in order to be on the same level" as the domestic students in his academic program.

The majority of the participants expressed that they believe that it is the primary responsibility of university staff to help alleviate feelings of social isolation that international graduate students experience, primarily through the advertising of events being held both on and off campus. As Stephen (Columbia, Ph.D.) shared during the focus group, in order to be involved on campus, international graduate students simply "need to know what is going on at the university." Though participants expressed that they mostly rely on their own social connections to remain aware of upcoming events, they wished that university staff did a better job with outreach efforts geared toward including the international graduate student population. It is important to note that social loneliness can also be a cyclical experience as it has the ability to affect and be affected by other types of loneliness, such as Interpersonal Loneliness. In both the focus groups sessions and interviews, participants shared that the host university should hold informational sessions geared toward cultural competency and inclusiveness. Female participant Jenn (Zambia, Ph.D.) shared that "The University should enlighten domestic students on that international students are different and ways to be respectful of one another." Jenn further explained that she had experiences where she was initially met with kindness until she spoke and an accent was heard. She said, "People look at me and think I'm African American, but when I talk, they say she's 
different. People should feel safe and sometimes you feel unsafe because you're different."

\section{Discussion}

This study's findings have the ability to broaden perspectives to include an understanding of the cyclical nature of xenophobia and just how interconnected stress and mental health are as it relates to this population. Although these findings are based off of the narratives of ten international graduate student participants at a single university, the data gathered has the potential to be applicable and implemented at other academic settings that house international graduate students. Furthermore, the findings are significant for non-international students to be aware of how they might be able to aid in the adjustment of international graduate students by being cognizant of and empathetic to their needs. To this end, a feasible recommendation would be for the host university to implement a pairing system, one domestic student to one international graduate student. This way, as adjustment issues arise for the international graduate student, the student representative assigned to them would be able to assist and potentially remediate.

The stigma that surrounds receiving mental health support is a major barrier in international graduate students deciding to seek help. The responsibility of destigmatizing the seeking of such services rests on the shoulders of the host university. Overall, emotional wellness is an area that host university staff must view as a primary concern for this population and work to ensure that there are proper staffing in place to meet both the mental and physical health needs of this population.

\section{Conclusion}

The themes that emerged speak to many areas of adjustment and the findings shed light on new issues of acculturation such as stereotypes and its relationship and effects on mental health. The experiences shared by the participants have the ability to, at the very least, initiate the discussion about ways in which university staff will be able to implement services that will hopefully bridge the gap between what is already being offered and what may be lacking. It is also the responsibility of community members to not only be tolerant of other cultures but accepting and kind in their treatment toward this population of students.

It is critical that university staff work toward ensuring that the international graduate student has acculturated into their new educational setting and feel safe and supported throughout the duration of their stay. Many of the participants shared how they felt more supported during their initial arrival at the host university and that the support faded as the semester went on. Therefore, all efforts in the form of programs and services for this population should be sustainable throughout the year. In order to ensure that this happens, there should be an effort undertaken on behalf of select university staff, instructors and educators to work to make the experiences of these visiting students a positive and fulfilling one.

\section{References}

Baba, Yoko, and Megumi Hosada. 2014. "Home Away Home: Better Understanding of the Role of Social Support in Predicting Cross-Cultural Adjustment among International Students." College Student Journal 48(1): 1-15.

Bai, Jieru. 2016. "Development and Validation of the Acculturative Stress Scale for Chinese College Students in the United States (ASSCS)." Psychological Assessment 28(4): 443-447, https://doi:10.1037/pas0000198.

Berry, John W. 2006. "Stress Perspectives on Acculturation." The Cambridge Handbook of Acculturation Psychology, (2006): 43-57, https://doi:10.1017/CBO9780511489891.007.

Billings, Meredith S., and Dawn Geronimo Terkla. 2014. "The Impact of the Campus Culture on Students' Civic Activities, Values, and Beliefs." New 
Directions for Institutional Research 2014, no. 162: 43-53, https://doi:10.1002/ir.20076.

Capielo, Cristalís, Edward A. Delgado-Romero, and Alan E. Stewart. 2015. "A Focus on an Emerging Latina/o Population: The Role of Psychological Acculturation, Acculturative Stress, and Coping on Depression Symptoms among Central Florida Puerto Ricans." Journal of Latina/o Psychology 3(4): 20923, https://doi:10.1037/lat0000039.

Chalungsooth, Pornthip, and Gregory R. Schneller. 2011. "Development of Translation Materials to Assess International Students Mental Health Concerns." Journal of Multicultural Counseling and Development 39(3): 180-91, https://doi:10.1002/j.2161-1912.2011.tb00150.x.

Chapdelaine, Raquel Faria, and Louise R. Alexitch. 2004. "Social Skills Difficulty: Model of Culture Shock for International Graduate Students." Journal of College Student Development 45(2): 167-84, https://doi:10.1353/csd.2004.0021.

Chen, Justin A., Lusha Liu, Xudong Zhao, and Albert S. Yeung. 2015. "Chinese International Students: An Emerging Mental Health Crisis." Journal of the American Academy of Child \& Adolescent Psychiatry 54(11): 879-80, https://doi:10.1016/j.jaac.2015.06.022.

Cross, Terry L. 1989. "Towards a Culturally Competent System of Care: A Monograph on Effective Services for Minority Children Who Are Severely Emotionally Disturbed." Washington, DC: CASSP Technical Assistance Center, Georgetown University Child Development Center,: 7-10.

Erichsen, Elizabeth A., and Doris U. Bolliger. 2010. "Towards Understanding International Graduate Student Isolation in Traditional and Online Environments." Educational Technology Research and Development 59(3): 309-26. https://doi:10.1007/s11423-010-9161-6.

Hendrickson, Blake, Devan Rosen, and R. Kelly Aune. 2011. “An Analysis of Friendship Networks, Social
Connectedness, Homesickness, and Satisfaction Levels of International Students." International Journal of Intercultural Relations 35(3): 281-95. https://doi:10.1016/j.ijintrel.2010.08.001.

Hirai, Reiko, Patricia Frazier, and Moin Syed. 2015. "Psychological and Sociocultural Adjustment of First-year International Students: Trajectories and Predictors." Journal of Counseling Psychology 62(3): 438-52, https://doi:10.1037/cou0000085.

Institute of International Education. 2015. "International Students by Academic Level, 2013/14 - 2014/15." Open Doors Report on International Educational Exchange. Retrieved from http://www.iie.org/opendoors.

Kim, Bryan S. K., and Michael M. Omizo. 2006. "Behavioral acculturation and enculturation and psychological functioning among Asian American college students." Cultural Diversity and Ethnic Minority Psychology 12(2): 245-258, http://dx.doi.org/10.1037/1099-9809.12.2.245

Mori, Sakurako Chako. 2000. "Addressing the Mental Health Concerns of International Students." Journal of Counseling \& Development 78(2): $\quad$ 137-44, http://doi:10.1002/j.15566676.2000.tb02571.x.

Shim, Gayoung, Henning Freund, Malte Stopsack, Annette Kämmerer, and Sven Barnow. 2013. "Acculturation, Self-construal, Mental and Physical Health: An Explorative Study of East Asian Students in Germany." International Journal of Psychology 295-303, http://doi:10.1002/ijop.12008.

Sullivan, Christopher, and Susan Kashubeck West. 2015. "The Interplay of International Students' Acculturative Stress, Social Support, and Acculturation Modes." Journal of International Students 5(1): 1-11. 